THE aim of this study was to assess whether interleukin-10 (IL-10) and/or transforming growth factor $\beta-1\left(T G F \beta_{1}\right)$ down regulate HLA-DR expression using the HT29 cell line as a model of colonic epithelial cells. HLA-DR expression was induced in HT29 cells with $\gamma$-interferon. The effects of IL-10 alone, TGF $\beta_{1}$ alone, and IL-10 and TGF $\beta_{1}$ in combination were studied. HLA-DR expression was assessed using flow cytometric analysis. $\gamma$-Interferon induced HLA-DR expression in a dose-dependent fashion. In the absence of $\gamma$-interferon, neither IL-10 nor TGF $\beta_{1}$ induced HLA-DR expression. In isolation, neither IL10 nor TGF $\beta_{1}$ downregulated HLA-DR expression. When IL-10 and TGF $\beta_{1}$ were added in combination, small $(6-30 \%)$ statistically significant reductions in HLA-DR expression were seen. The biological significance is unclear.

Key words: Interleukin-10, Transforming Grow th Factor $\beta$ 1, $\gamma$-Interferon, HLA-DR, HT29 cell culture

\section{The effect of interleukin-10 and transforming growth factor $\beta-1$ on HLA-DR expression in colonic epithelial cells}

\author{
M. J. Zimmerman, ${ }^{1, C A}$ G. R. Radford-Smith ${ }^{2}$ and \\ D. P. Jewell ${ }^{3}$
}

${ }^{1}$ Gastroenterology Department, Royal Perth Hospital, Wellington Street, Perth, Western Australia, Australia 6001; ${ }^{2}$ Department of Gastroenterology, Royal Brisbane Hospital, Herston Road, Brisbane, Queensland, Australia 4029; ${ }^{3}$ Gastroenterology Unit, Radcliffe Infirmary, Woodstock Road, Oxford, OX2 6HE, UK

\author{
${ }^{\mathrm{CA}}$ Corresponding Author \\ Tel: $(+61) 892242244$ \\ Fax: (+61) 892243511
}

\section{Introduction}

HLA-DR molecules are cell surface heterodimers that act as immune recognition molecules. A variety of antigen-presenting-cells present antigen in association with HLA-DR to lymphocytes. This interaction leads to lymphocyte activation and proliferation, and thus promotes inflammatory responses. ${ }^{1}$ In addition to constitutive expression on a variety of cell types including lymphocytes, macrophages, vascular endothelium and some epithelial cells, ${ }^{2}$ expression of HLA$\mathrm{DR}$ molecules is induced in a much wider range of cell types in the presence of inflammation. ${ }^{3}$

Under normal conditions, HLA-DR molecules are not expressed by colonic epithelium, ${ }^{4}$ however, colonic epithelial cell expression of HLA-DR is seen in a variety of inflammatory bowel diseases. ${ }^{5,6}$ In vitro studies have shown that HLA-DR-bearing colonic epithelial cells can present antigen to mucosal lymphocytes. ${ }^{7,8}$ It is thus likely that HLA-DR expression by colonic epithelial cells is an important step in the generation of mucosal immune responses.

The mechanisms that regulate colonic epithelial cell expression of HLA-DR are being defined. Induction of HLA-DR is mediated by pro-inflammatory cytokines such as $\gamma$-interferon. ${ }^{3,9} \gamma$-Interferon has been widely used to induce HLA-DR expression in human gastrointestinal carcinoma cell lines. ${ }^{10-12}$ The mechanisms by which colonic epithelial cell HLA-DR expression is downregulated when mucosal inflammation resolves have not been identified.

Some cytokines have immunosuppressive properties, some of which may be due to downregulation of HLA-DR expression in antigen presenting cells. Interleukin-10 (IL-10) and transforming growth factor $\beta$ (TGF $\beta)$ are of particular interest. IL-10 has a variety of inhibitory actions including inhibition of Tymphocyte activation/function as well as inhibition of the production of chemokines and cytokines. ${ }^{13-15}$ IL-10 inhibits $\gamma$-interferon-induced expression of MHC Class II antigens in a variety of cell types. ${ }^{16-19}$ Mice that are deficient in the IL-10 gene develop chronic enterocolitis. ${ }^{20}$ TGF $\beta$ is present throughout the gastrointestinal mucosa ${ }^{21}$ and has a variety of inhibitory functions such as inhibition of epithelial cell proliferation. ${ }^{22}$ TGF $\beta$ also down regulates HLA-DR expression in a variety of cell types, including a colonic carcinoma cell line. ${ }^{23}$ As with the IL-10 'knockout' mouse, mice with disrupted TGF $\beta$ genes develop multifocal chronic inflammation which includes involvement of the gastrointestinal tract. ${ }^{24}$ With these observations in mind, we hypothesized that IL-10 and/or TGF $\beta$ downregulate colonic epithelial HLA-DR expression.

The aim of this series of experiments is to test whether IL-10 and TGF $\beta$ down-regulate $\gamma$-interferon- 
induced HLA-DR expression in an experimental model of colonic epithelium. The cell line selected for use in this study (HT29/19a clone) is a well differentiated human colonic carcinoma cell line that forms monolayers with ultrastructural and functional similarities to normal colonic epithelium. ${ }^{25-28}$ The HT29 cell line has been used in previous studies examining the effects of different agents on colonic epithelial cell expression of HLA-DR ${ }^{9,10,12}$

\section{Methods}

\section{Cell line}

The HT29/19a colonic carcinoma cell line was a gift of Professor Laboisse. ${ }^{26}$ The stock cultures were maintained at $37^{\circ} \mathrm{C}$ in an atmosphere of $5 \% \mathrm{CO}_{2}$ in Dulbecco's modified Eagle medium (DMEM) supplemented with glucose $4500 \mathrm{mg} / \mathrm{l}, 10 \%$ heat inactivated fetal calf serum and $1 \%$ antibiotic solution (penicillin $10000 \mathrm{IU} / \mathrm{ml}$ and streptomycin $10000 \mathrm{U} / \mathrm{ml}$ ).

\section{Cytokines}

Human $\gamma$-interferon, IL-10 and TGF $\beta_{1}$ were purchased from Genzyme (Kent, UK). All cytokines were prepared as sterile, filtered solutions in culture media, and then stored frozen. Although specific bio-assays of these preparations were not performed for this series of experiments, all of these cytokine preparations demonstrated biological activity in cell culture systems used by other workers in our group.

\section{Experimental incubations}

For each experiment, HT29/19a cells were harvested from the stock cultures and added to separate $4.5 \mathrm{~cm}^{2}$ wells in a 12-well culture plate. The cells were then incubated for $72 \mathrm{~h}$. Each experiment was done in quadruplicate.

\section{Experimental protocols}

HLA-DR expression was induced by $\gamma$-interferon. Experiments were performed using concentrations of $\gamma$-interferon of $10 \mathrm{U} / \mathrm{ml}$ and $100 \mathrm{U} / \mathrm{ml}$. The effects of IL10 and TGF $\beta_{1}$ were assessed over cytokine concentrations of $0,1,10$ and $100 \mathrm{U} / \mathrm{ml}$. Three series of experiment were performed. Firstly, the effect of IL-10 was examined. Secondly, the effect of TGF $\beta_{1}$ was examined, and thirdly, the effect of IL-10 and TGF $\beta_{1}$ in combination was examined. Within each experimental series, two further experiments were set up. In one set of cultures, cytokine was added at the same time as $\gamma$-interferon was added (co-incubation). In a separate set of cultures, cytokine was added $24 \mathrm{~h}$ prior to the addition of $\gamma$-interferon (pre-incubation).

A further series of experiments were performed to examine the hypothesis that mucosal lamina propria lymphocytes from uninflamed colonic mucosa may inhibit colonic epithelial cell expression of HLA-DR Colonic mucosal lamina propria lymphocytes (LPL) were isolated from uninflamed colonic mucosa obtained from surgical resection specimens using a previously described protocol. ${ }^{29}$ All tissue was obtained from normal appearing mucosa at least $5 \mathrm{~cm}$ from any macroscopic disease. The diagnoses of the patients included carcinoma (six patients) and ischaemic colitis (one patient). The isolated LPL were maintained at a concentration of $10^{6}$ cells per $\mathrm{ml}$ in RPMI culture media supplemented with $10 \%$ heat inactivated fetal calf serum and $1 \%$ antibiotic solution (penicillin $10000 \mathrm{IU} / \mathrm{ml}$ and streptomycin $10000 \mathrm{U} / \mathrm{ml}$ ). Following isolation, the LPL were maintained in culture at $37^{\circ} \mathrm{C}$ in an atmosphere of $5 \% \mathrm{CO}_{2}$ for $24 \mathrm{~h}$. The cultures were then spun down at $750 \times$ $g$, and the supernatants collected and frozen at $-70^{\circ} \mathrm{C}$. The LPL supernatants were thawed at $37^{\circ} \mathrm{C}$ and diluted with supplemented DMEM at a ratio of $1: 2$ (supernatant:DMEM). This mix ture was then used to culture HT29/19a cells in a similar fashion to the cytokine experiments. The control cultures were maintained in a 1:2 mix ture of supplemented RPMI and DMEM Due to limited volumes of supernatant, this experiment was only done using $\gamma$-interferon of $100 \mathrm{U} / \mathrm{ml}$. The composition of the supernatants was not evaluated.

\section{Flow cytometry}

At the end of the incubation period, the monolayers were disrupted and single cell suspensions created using EDTA. Cell viability was assessed by Trypan Blue staining, and any samples with viability was less than $90 \%$ were discarded. The cells were then stained with fluoroscein isothiocyanate (FITC)-conjugated antiHLA-DR (Dako), a mouse anti-human monoclonal antibody to the $\beta$ chain of HLA-DR. FITC-conjugated anti-IgG1 (Becton Dickinson) was used as the negative isotype control. The cells were fixed with $1 \%$ paraformaldehyde in $\mathrm{PBS} / 0.1 \%$ sodium azide, and analysed within 2-4 days.

The samples were analysed using a Becton Dickinson flow cytometer using LYSIS II software. Fluorescence histograms for the anti-HLA-DR cells were generated for each sample. Five thousand cells per gate were counted. The data recorded included (a) the percentage of cells of each sample that showed fluorescence with the FITClabelled anti-HLA-DR, and (b) the mean/median fluorescence intensity of the stained cells.

\section{Statistical analysis}

The data from each experimental series was analysed using a one-way analysis of variance using Excel ${ }^{\circledR}$ (Microsoft) software. 


\section{Results}

\section{Effect of $\gamma$-interferon}

Cells were $70-80 \%$ confluent at the time of harvest. The percentage of cells staining positive for HLA-DR increased with increasing dose of $\gamma$-interferon, although no further increases were noted at concentrations of $\gamma$-interferon in excess of $50 \mathrm{U} / \mathrm{ml}$. Within the population of cells staining positive for HLA-DR, there were no significant differences between median or mean fluorescence intensity with cells exposed to different doses of $\gamma$-interferon. The viability of cells in all experiments ranged from $92 \%$ to $95 \%$ with no significant differences observed across any of the different interventions.

Some variation in the sensitivity of the cells to $\gamma$-interferon was noted from passage-to-passage. This occurred despite the use of identical reagents and culture protocols, and in the absence of infection. Similar variation has been seen by other workers using HT29 cell line. ${ }^{12}$ In view of this observation, the direct comparison of results obtained from different passage generations is invalid. The cellular basis of this variability is unclear.

\section{Effects of isolated IL-10 and TGF $\beta-1$}

Neither IL-10 nor TGF $\beta_{1}$ in isolation, in the absence of $\gamma$-interferon, induced expression of HLA-DR in HT29/19a cells. Neither co-incubation nor pre-incubation with IL-10 resulted in any significant differences in the percentage of cells staining positive for HLA-DR at either concentration of $\gamma$-interferon (Fig. 1 ). Within the population of cells staining positive for HLA-DR, there were no significant differences between median or mean fluorescence intensity with cells exposed to different doses of IL-10 at either concentration of $\gamma$-interferon. In identical experiments, isolated TGF $\beta_{1}$ had no effect on HLADR expression (Fig. 2).

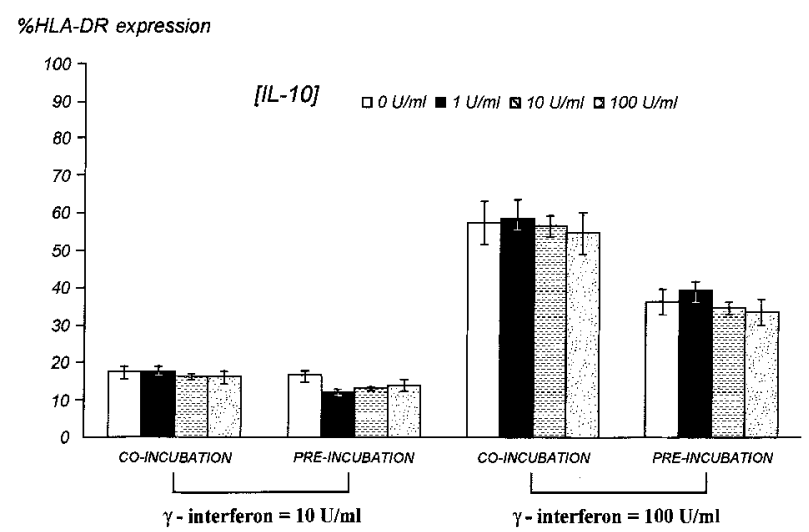

FIG. 1. The effect of interleukin-10 on $\gamma$-interferon induced HLA-DR expression. (The error bars represent \pm 1 standard deviation.) For all ANOVA, $P$-value $>0.05$.

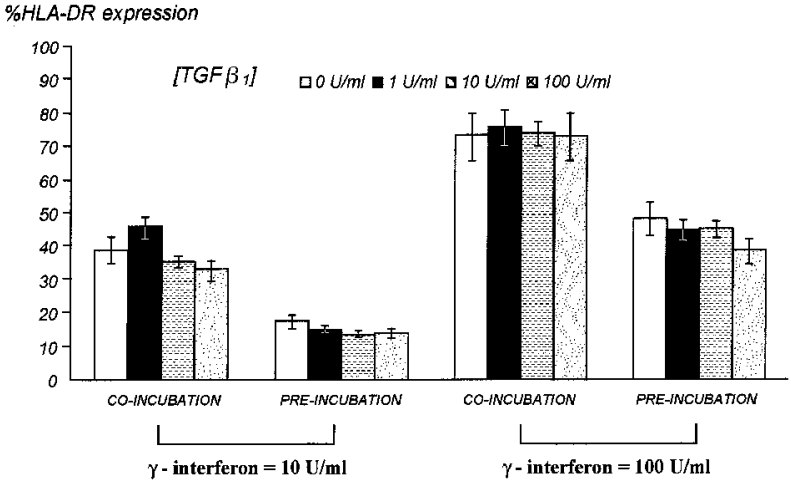

FIG. 2. The effect of transforming growth factor $\gamma-1$ on $\gamma$-interferon induced HLA-DR expression. (The error bars represent \pm 1 standard deviation.) For all ANOVA, $P$-value $>0.05$.

\section{Effects of combination IL-10 and TGF $\beta-1$}

When IL-10 and TGF $\beta_{1}$ were added in combination in the absence of $\gamma$-interferon, no expression of HLA-DR was observed. In the presence of $\gamma$-interferon, the combination of IL-10 and TGF $\beta_{1}$ significantly reduced the percentage of cells expressing HLA-DR in a dose dependent fashion (Fig. 3). The magnitude of the maximum reduction in percentage of cells expressing HLA-DR was greater in the groups incubated with the lower concentration of $\gamma$-interferon. Despite achieving statistical significance, the absolute reductions in expression of HLA-DR were small in each group $(6-30 \%)$. The magnitude of the reductions in percentage of cells expressing HLA-DR was greater in the pre-incubation groups than in the co-incubation groups (for $\gamma$-interferon $=10 \mathrm{U} / \mathrm{ml}, 30 \%$ vs. $6 \%$ for $\gamma$-interferon $=100 \mathrm{U} / \mathrm{ml}, 12.1 \%$ vs. $8.3 \%$ ). Within the population of cells staining positive for HLA-DR, there were no significant differences between median or mean fluorescence intensity with cells exposed to different doses of IL-10 and TGF $\beta_{1}$ at either concentration of $\gamma$-interferon.

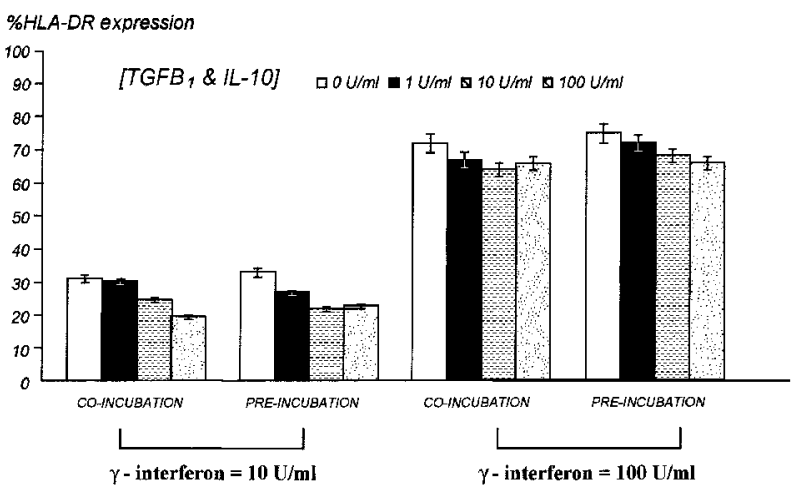

FIG. 3. The effect of combination interleukin-10 and transforming growth factor $\gamma$-1 on $\gamma$-interferon induced HLA-DR expression. (The error bars represent \pm 1 standard deviation.) ${ }^{*} P$-value for ANOVA $<0.05$. 
Effect of LPL supernatants on HT29/19A HLA-DR expression

No significant differences in HLA-DR expression were observed between cells cultured with LPL supernatant/DMEMculture medium and cells cultured with DMEM culture medium alone.

\section{Discussion}

On the basis of these results, neither TGF $\beta_{1}$ nor IL-10 acting in isolation downregulate $\gamma$-interferon-induced expression of HLA-DR within this experimental syste $\mathrm{m}$. The re are no other published data examining the effect of IL-10 on expression of HLA-DR in a colonic epithelial cell line. Previous studies using TGF $\beta_{1}$ have shown conflicting results. Darley et $a .^{11}$ demonstrated that TGF $\beta_{1}$ inhibited induced expression of HLA-DR in a variety of cell lines. However, they found that nine different colorectal cell lines (including HT29) were resistant to the inhibitory effects of $\mathrm{TGF} \beta_{1}$ on both epithelial prolife ration and epithelial expression of MHC molecules including HLA-DR. In contrast, Donnet-Hughes et al. ${ }^{12}$ found that $\mathrm{TGF}_{2}$ downregulated $\gamma$-interferon-induced HLA-DR expression by up to $75 \%$ Several factors may explain the discrepancies between these different studies.

Firstly, the absence of inhibitory effects seen in the current study may reflect limitations of the experimental model. As Darley et al. ${ }^{11}$ demonstrated, there is wide variation in the sensitivity of different cell lines to the effects of specific cytokines. It is interesting to note that even using the same cell line (HT29), different groups have generated diverse results. For example, our group has previously found that HT29 cells grown in glucose containing media do not show induction of HLA-DR on exposure to $\gamma$-interferon, ${ }^{30}$ but this lack of responsiveness has not been found by other workers, ${ }^{12}$ or in our experience with the current clone of HT29. These discrepancies may reflect differences in the degree of differentiation of the HT29 clones, as glucose influences the differentiation of these cells in culture. ${ }^{25,27,30}$ Discrepancies between the results of different groups may represent subtle differences in the functional characteristics between the different clones of HT29 cells used.

A further confounding factor is that use of colorectal carcinoma cell lines is only an approximation of the functional behaviour of non-malignant cells. Recent work has shown some colorectal carcinoma cell lines, including HT29, have a mutation in the TGF $\beta$ receptor that renders them insensitive to the effects of TGF $\beta .31$ The ideal experimental model would be to use non-malignant epithelial cells. Whilst isolation protocols for human colonic epithelial cells are described, ${ }^{7,32,33}$ it has been difficult to maintain non-malignant colonic epithelial cells in long-term cell culture. ${ }^{34}$
Methodological aspects of the experimental model may also have contributed to the failure to observe any inhibitory effects of isolated cytokines in the current work. One factor worth consideration is the incubation time used. Donnet-Hughes et al. ${ }^{13}$ incubated cultures for $24-48 \mathrm{~h}$ and changed the cytokine containing media daily. In contrast, the cell cultures in our series were maintained for $72 \mathrm{~h}$ without any replenishment of the media. As cytokines are labile and have very short half lives in vivo, it is conceivable that the relatively long incubation time and the lack of replenishment of the cytokines may have reduced the sensitivity of the experimental system for detection of cytokine-mediated changes in HLA-DR expression.

In contrast to the effects of TGF $\beta_{1}$ and IL-10 alone, small reductions in induced HLA-DR expression were observed when both cytokines were added in combination. The magnitude of the reductions in HLA-DR expression are relatively small compared with those observed by other workers. ${ }^{13}$ As has been observed in a previous study, ${ }^{12}$ the magnitude of the reduction in HLA-DR expression is greater when the induction signal is smaller (i.e. at lower doses of $\gamma$-interferon that are not within the saturated portion of the $\gamma$-interferon/ HLA-DR expression dose response curve). Although the observed reductions in HLA-DR expression may represent a genuine biological effect, the absolute magnitude of the reduction in HLA-DR expression is small and may simply represent non-specific effects of having ex tra peptide in the culture media.

It is biologically plausible that TGF $\beta_{1}$ and IL-10 acting in combination have much greater inhibitory effects on HLA-DR expression than either cytokine acting alone. It has been shown that TGF $\beta_{1}$ and IL-10 act at different levels of cellular function. For example, IL-10 has been shown to downregulate macrophage TNF- $\alpha$ production by inhibiting production of TNF- $\alpha$ mRNA whereas TGF $\beta_{1}$ inhibits macrophage TNF- $\alpha$ production by inhibiting TNF- $\alpha$ release. ${ }^{35}$

It is also possible that the small reductions in HLADR expression demonstrated in the current study have no relevance in vivo. Other workers have show $n$ that the inhibitory effects of cytokines such as IL-10 are celltype specific and also depend on the type of inducing signals used. ${ }^{17} \mathrm{~A}$ major limitation of the current experimental model is that it ignores the interactions of other cell types found within in the mucosal microenvironment in vivo. It is possible that the antiinflammatory properties of IL-10 and TGF $\beta_{1}$ in vivo are mediated through other cell types such as macrophages and neutrophils, ${ }^{14}$ and that epithelial cell HLA-DR expression is not the direct target of these cytokines in vivo. Even if the epithelial cells are not the direct targets of IL-10 and TGF $\beta_{1}$, these cytokines may inhibit epithelial cell HLA-DRex pression indirectly. For example, IL-10 is a potent inhibitor of monocyte production of $\gamma$-interferon, ${ }^{36}$ which will in turn inhibit the HLA-DR expression by epithelial cells. 
Finally, one can speculate that an 'off' signal for colonic epithelial HLA-DR expression is not necessary in vivo because of the kinetics of the colonic epithelial turnover. The colonic epithelium is constantly turning over with continuous loss of epithelial cells and replacement of these cells from proliferation in the colonic crypts. In this system, the loss of inflammatory signals such as $\gamma$-interferon maybe all that is necessary to result in the re-appearance of HLADR-negative epithelial cells. Our observation that lamina propria lymphocyte supernatants from uninflamed mucosa do not downregulate $\gamma$-interferoninduced HLA-DR expression is consistent with this hypothesis.

In summary, IL-10 and TGF $\beta_{1}$ in combination, but not acting alone, directly downregulate $\gamma$-interferoninduced HLA-DR expression in colonic epithelial cells. The magnitude of these effects are small, and may reflect limitations of the specific experimental model. The biological relevance of these findings is unclear. Given the potential therapeutic significance of IL-10 and TGF $\beta_{1}$ in controlling mucosal inflammation, further investigation is warranted.

\section{References}

1. Thorsby E. Structure and function of HLA molecules. Transplant Proc 1987; 19: 29-35.

2. Daar AS, Fuggle SV, Fabre JW, Ting A, Morris PJ. The detailed distribution of MHC class II antigens in normal human organs. Transplantation 1984; 38: 292-298.

3. Benoist C, Mathis D. Regulation of major histocompatibility complex class-II genes: X, Y and other letters of the alphabet. Ann Rev Immuno 1990; 8: 681-715.

4. Bland P. MHC class II expression by gut epithelium. Immunol To day 1988; 9: 174-178

5. Selby WS, Mason DW, Jewell DP. Expression of HLA-DR antigens by colonic epithelium in inflammatory bowel disease. Clin Exp Immunol 1983; 53: 614-618.

6. McDonald GB, Jewell DP. Class II antigen (HIA-DR) expression by intestinal epithelial diseases of the colon. J Clin Pathol 1987; 40: 312-317.

7. Panja A, Barone A, Mayer L. Stimulation of lamina propria lymphocytes by intestinal epithelial cells: evidence for recognition of nonclassical restriction elements. J Exp Med 1994; 179: 943-950.

8. Blumberg RS, Probert IS, Christ AD, et al. The role of epithelial cells. In: Tytgat GNJ, Bartelsman JFWM, van Deventer SJH, eds. Inflammatory Bowel Diseases: Falk Symposium 85. Dordrecht: Kluwer, 1995.

9. Lowes JR, Radwan P, Priddle JD, Jewell DP. Characterisation and quantification of mucosal cytokine that induces epithelial histocompatibility locus antigen-DR expression in inflammatory bowel disease. Gut 1992; 33: 315-319.

10. Crotty B, Hoang P, Dalton HR, Jewell DP. Salicylates used in inflammatory bowel disease and colchicine impair $\gamma$-interferon induced HLA-DR expression. Gut. 1992; 33: 59-64.

11. Darley R, Morris A, Passas J, Bateman W. Interactions between $\gamma$-interferon and retinoic acid with transforming growth factor $\beta$ in the induction of immune recognition molecules. Cancer Im munol Immunother. 1993; 37: 112-118.

12. Donnet-Hughes A, Schiffrin EJ, Huggett AC. Expression of MHC antigens by intestinal epithelial cells. Effect of transforming grow th factor beta-2 (TGFß2). Clin Exp Immunol. 1995; 99: 240-244.

13. Mosmann TR. Properties and function of interleukin-10. Adv Immunol. 1994; 56: 1-26

14. De Vries JE. Interleukin-10: immunosuppressive and anti-inflammatory activities. In: Tytgat GNJ, Bartelsman JFWM, van Deventer SJH, eds. Inflam matory Bowel Diseases: Falk Symposium 85. Dordrecht: Kluwer 1995.
15. Isomaki P, Luukkainen R, Saario R, Toivanen P, Punnonen J. Interle ukin-10 functions as an antiinflammatory cytokine in rheumatoid synovium. Arthr Rheum 1996; 39: 386-395.

16. de Waal Malefyt R, Haanen J, Spits $\mathrm{H}$, et al. Interleukin 10 (IL-10) and viral IL-10 strongly reduce antigen-specific human $T$ cell proliferation by diminishing the antigen-presenting capacity of monocytes via downregulation of class II major his tocompatibility complex expression. J Exp Med 1991; 174: 915-924.

17. Frei K, Lins H, Schwerdel C, Fontana A. Antigen presentation in the central nervous system. The inhibitory effect of IL-10 on MHC class II expression and production of cytokines depends on the inducing signals and the type of cell analysed. I Im munol 1994; 152: 2720-2728.

18. Peguet-Navarro J, Moulon C, Caux C, Dalbiez-Gauthier C, Banchereau J, Schmitt D. Interleukin-10 inhibits the primary allogeneic T cell response to human epidermal Langerhans cells. Eur J Immunol. 1994; 24:884-891

19. Boorste in SM, Elner SG, Meyer RF, et al. Interleukin-10 inhibition of HLADR expression in human herpes stromal keratitis. Ophthalmology 1994; 101:1529-1535

20. Kuhn R, Lohler J, Rennick D, Rajewsky K, Muller W. Interleukin10-deficient mice develop chronic enterocolitis. Cell 1993; 75 : 263-274.

21. Avery A, Paraskeva C, Hall P, Flanders KC, Sporn M, Moorghen M TGFbeta expression in the human colon: differential immunostaining along crypt epithelium. Br J Cancer 1993; 68: 137-139.

22. Dignass AU, Podolsky DK. Peptide grow th factors - implications for IBD. In: Rachmilewitz D. ed. Inflammatory Bowel Diseases - 1994. Dordrecht: Kluwer, 1994.

23. Suardet L, Gaide AC, Calmes JM, et al. Responsiveness of three newly established human colorectal cancer cell lines to transforming growth factors beta 1 and beta 2. Cancer Res 1992; 52: 3705-3712.

24. Shull MM, Ormsby I, Kier AB, et al. Targeted disruption of the mouse transforming growth factor $\beta 1$ gene results in multifocal inflammatory disease. Nature 1992; 359: 693-699.

25. Pinto M, Appay M, Simon-Assman N, et al. Enterocytic differentiation of cultured human colon cancer cells lines by replacement of glucose by galactose in the medium. Biol of the Cell 1982; 44: 193-196.

26. Augeron C, Laboisse CC. Emergence of permanently differentiated cell clone in a human colonic carcinoma cell line after treatment with sodium butyrate. Cancer Res. 1984; 44: 3961-3969

27. Zweibaum A, Pinto M, Chevalier G, et al. Enterocytic differentiation of a subpopulation of the human colon tumour cell line HT-29 selected for grow th in sugar free medium and its inhibition by glucose. J Cell Physiol 1985; 122: 21-29.

28. Phillips JO, Everson MP, Moldoveau Z, Lue C, Mestecky J. Synergistic effect of IL 4 and IFN- $\gamma$ on the expression of polymeric Ig receptor (secretory component) and IgA binding by human epithelial cells. $J$ Immunol 1990; 145: 1740-1744

29. Dalton HR, Hoang P, Jewell DP. Antigen induced suppression in peripheral blood and lamina propria mononuclear cells in inflammatory bowel disease. Gut 1992; 33: 324-330

30. Lowes JR Cytokines in inflammatory bowel disease. PHd Thesis, Cambridge 1992

31. Markowitz S, Wang J, Myeroff L, et al. Inactivation of the type IITGF-beta receptor in colon cancer cells with microsatellite instability. Science 1995; 268: 1336-1338

32. Mayer L, Shlien R. Evidence for function of Ia molecules on gut epithelial cells in man. J Exp Med. 1987; 166: 1471-1483

33. Lundqvist C, Hammarstrom ML, Athlin L, Hammarstrom S. Isolation of functionally active intraepithelial lymphocytes and enterocytes from human small and large intestine. J Immunol Methods. 1992; 152: 253-263

34. Fonti R, Latella G, Bises G, Magliocca F, Nobili F, Caprilli R, Sambuy Y. Human colonocytes in primary culture: a model to study epithelial growth, metabolism and differentiation. Int J Colorectal Dis 1994; 9: $13-22$

35. Bogdan C, Nathan C. Modulation of macrophage function by transforming grow th factor beta, interleukin 4 and interleukin-10. Ann NY Acad Sci 1993; 685: 713-739.

36. de Waal Malefyt R, Abrams J, Bennett B, Figdor CG, de Vries JE. Interleukin 10 (IL-10) inhibits cytokine synthesis by human monocytes: an autoregulatory role of IL-10 produced by monocytes. J Exp Med 1991; 174: $1209-1220$

ACKNOWLEDGEMENT. This work was presented as a poster at the 1996 Digestive Diseases Week Meeting in San Francisco in May 1996.

Received 3 September 1997; accepted in revised form 5 November 1997 


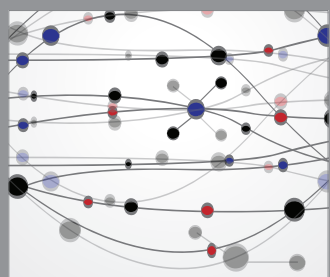

The Scientific World Journal
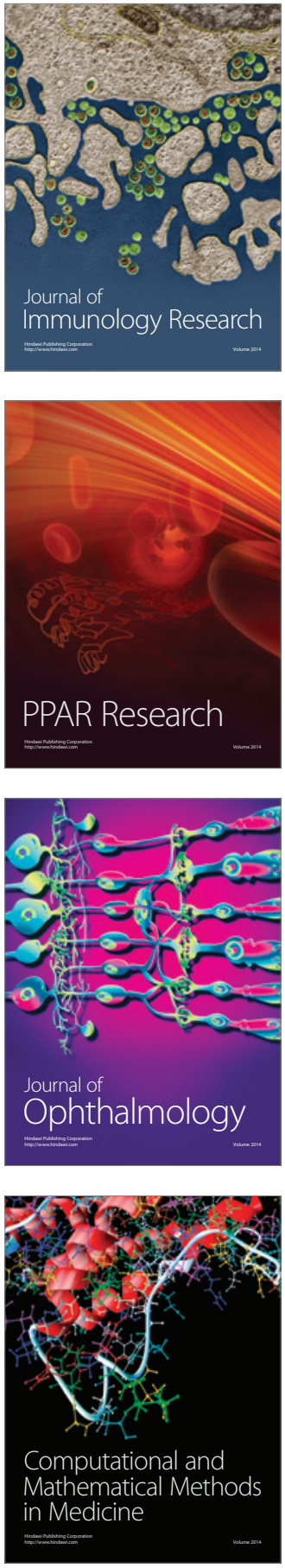

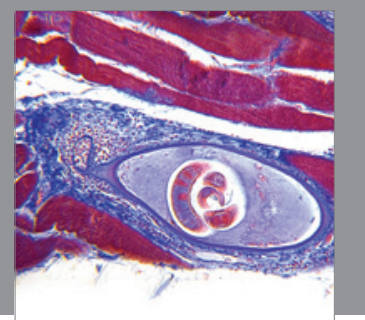

Gastroenterology

Research and Practice
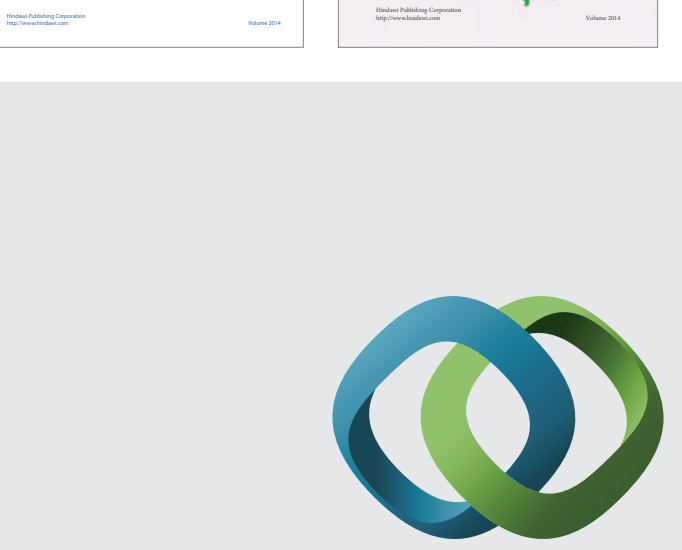

\section{Hindawi}

Submit your manuscripts at

http://www.hindawi.com
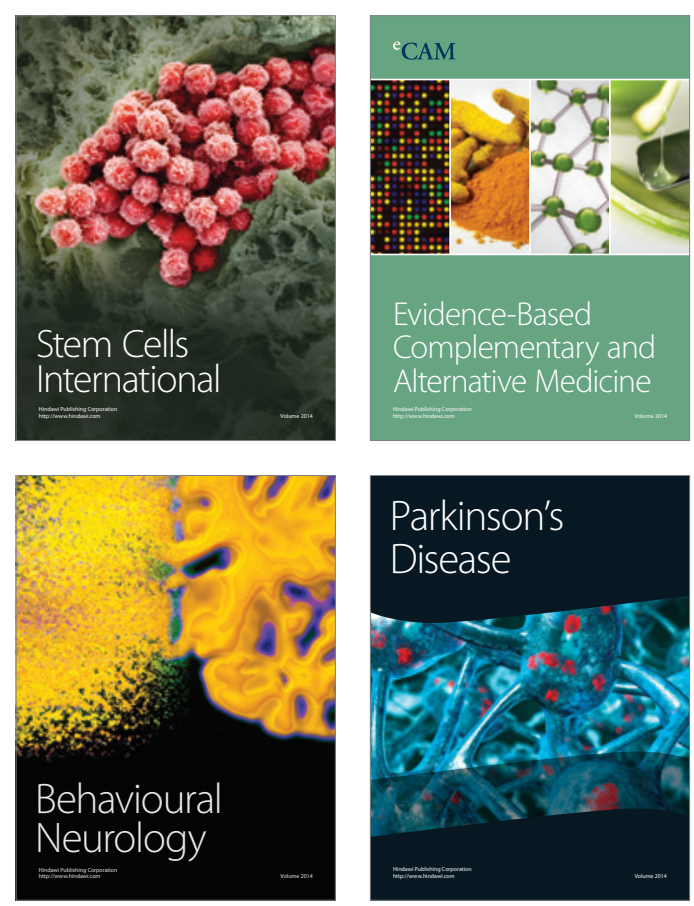

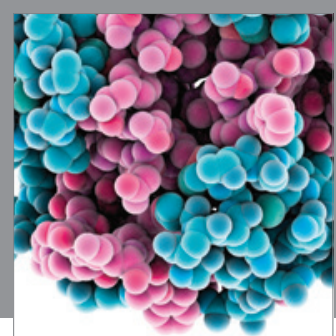

Journal of
Diabetes Research

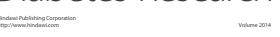

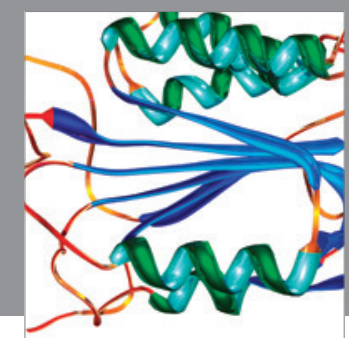

Disease Markers
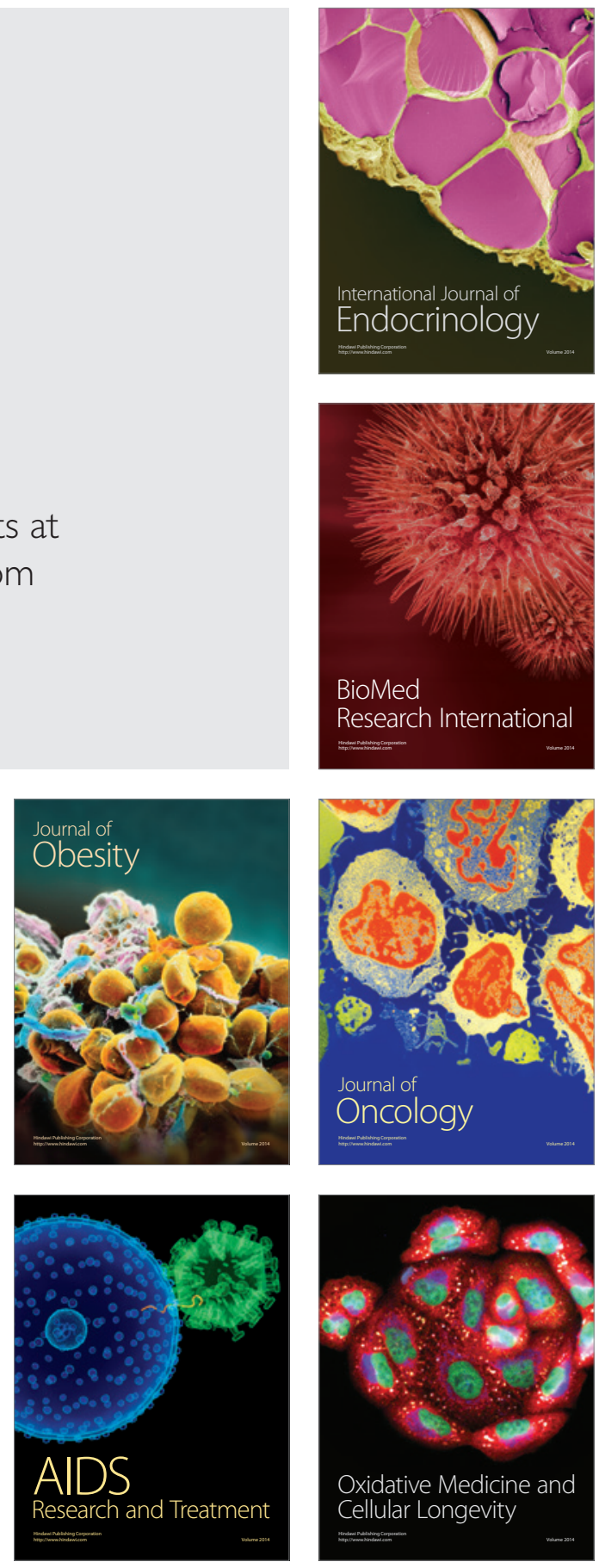